Check for updates

Cite this: Mater. Chem. Front., 2019, 3, 806

\title{
Antibacterial supramolecular polymers constructed via self-sorting: promoting antibacterial performance and controllable degradation $\dagger$
}

\author{
Yuchong Yang, ${ }^{a}$ Hao Hu, ${ }^{a}$ Linghui Chen, ${ }^{a}$ Haotian Bai, ${ }^{b}$ Shu Wang, ${ }^{b}$ \\ Jiang-Fei Xu (D) *a and Xi Zhang (D) ${ }^{a}$
}

\begin{abstract}
An antibacterial supramolecular polymer is developed that exhibits enhanced antibacterial efficacy and controlled degradability. To this end, a water-soluble bifunctional monomer bearing two naphthalene moieties and a phenylbenzene moiety, as well as a small molecule with antibacterial activity were synthesized. The side-chain antibacterial supramolecular polymer was fabricated through self-sorting of the bifunctional monomer, the small-molecule antibacterial agent, and cucurbit[8]uril. It displayed enhanced antibacterial efficacy against ampicillin-resistant $E$. coli owing to the local enrichment effect. The controlled degradation of the antibacterial supramolecular polymer could well regulate its antibacterial performance from high to low activity. It is anticipated that this line of research may lead to novel antibacterial supramolecular materials for building degradable antibiotics with enhanced antibacterial efficacy to fight against drug-resistant bacteria.
\end{abstract}

Received 17th January 2019, Accepted 4th March 2019

DOI: $10.1039 / c 9 q m 00028 c$

rsc.li/frontiers-materials each other via non-covalent interactions. ${ }^{28-56}$ By construction of supramolecular polymers, functional monomers can be linked together through reversible non-covalent interactions. Therefore, we assume that if small-molecule antibiotics could be linked together to form supramolecular polymers, the antibacterial efficacy could be significantly enhanced owing to the local enrichment effect. Besides, benefiting from the dynamicity and reversibility of supramolecular interactions, such antibacterial supramolecular polymers can be controllably degraded. Thus, enhanced antibacterial efficacy and degradability of antibacterial materials could be realized by fabricating antibacterial supramolecular polymers.

Herein, we attempted to construct a side-chain antibacterial supramolecular polymer via a self-sorting strategy. Self-sorting is a self-assembly process in which molecules are endowed with the ability to selectively and specifically form complexes with their own recognition units within a complex mixture. ${ }^{57-64}$ It has been reported that supramolecular polymers with controlled structure and molecular weight can be constructed through the self-sorting strategy. ${ }^{65,66}$ By employing this strategy, we designed a side-chain antibacterial supramolecular polymer, by which antibacterial agents could be grafted to the supramolecular polymer backbone as the side chains. Then antibacterial agents could be locally enriched for promoting antibacterial performance. Moreover, the backbone of the antibacterial supramolecular polymer could be controllably degraded, thus reducing the antibacterial activity in case of need. The architecture of the antibacterial 


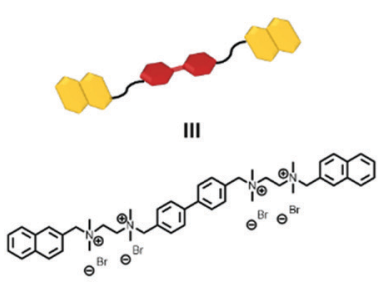

Np-PhDi-Np

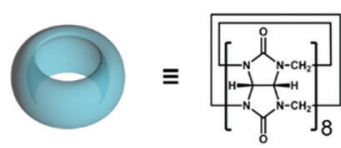

$\mathrm{CB}[8]$
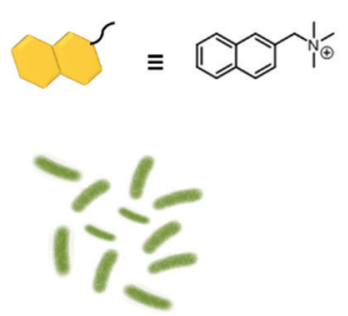

E.coli
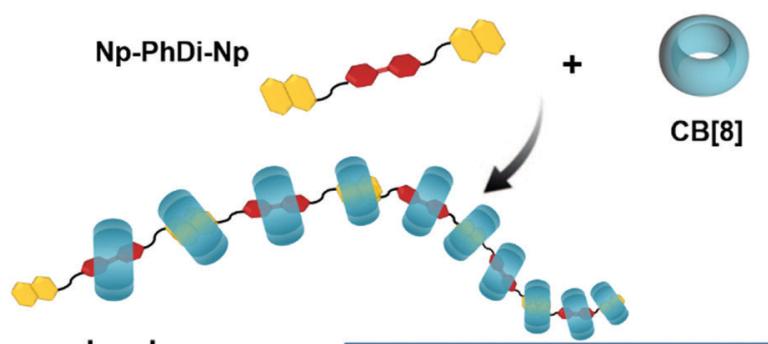

Supramolecular polymer backbone
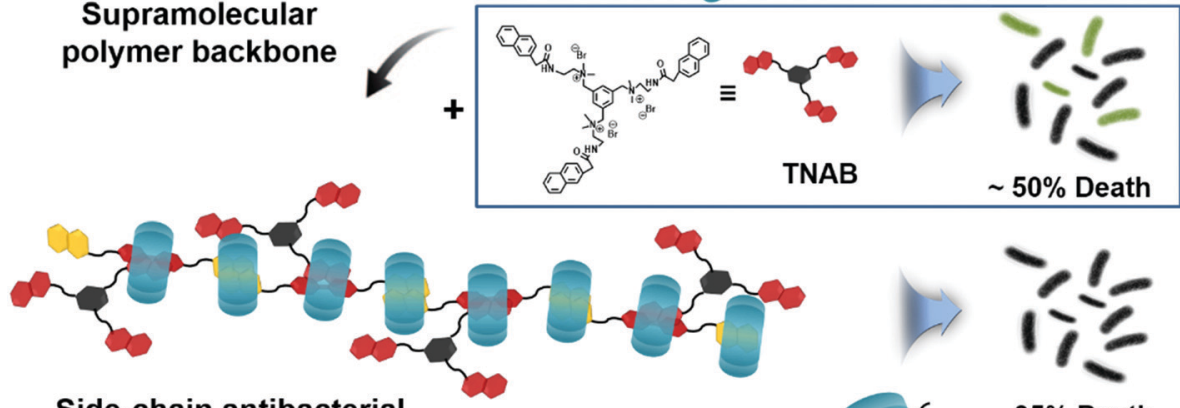

Side-chain antibacterial supramolecular polymer
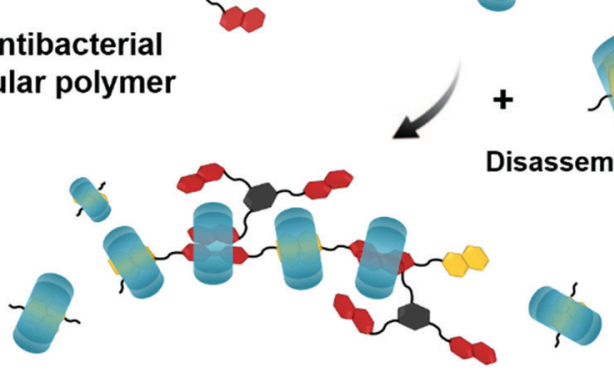

isassembling agent (DA)

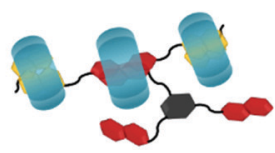

Scheme 1 Chemical structures of building blocks and schematic illustration of the fabrication of side-chain antibacterial supramolecular polymer.

supramolecular polymer consisted of two parts, the supramolecular polymer backbone and the side-chain antibacterial agents. As shown in Scheme 1, a bifunctional monomer (Np-PhDi-Np), containing two naphthalene ( $\mathrm{Np}$ ) moieties and a phenylbenzene (PhDi) moiety, was designed and synthesized to construct the supramolecular polymer backbone through the host-guest interaction of Np-PhDi-Np and cucurbit[8] uril (CB[8]).

A small molecule with antibacterial activity (TNAB) containing naphthalene acetamide (NpAM) moieties could be grafted to the supramolecular polymer backbone as side chains via self-sorting. The hydrophobic NpAM moieties of TNAB could insert into the membranes of bacteria for bacterial membranolysis. By locally enriching the TNAB on the supramolecular polymer backbone, the capacity for bacterial membranolysis may be remarkably increased. The degradation of the antibacterial supramolecular polymer could be realized by addition of a disassembling agent. Therefore, we may fabricate the antibacterial supramolecular polymer with tailor-made antibacterial efficacy and degradability.

\section{Results and discussion}

The fabrication of the supramolecular polymer backbone through the host-guest interaction of $\mathrm{Np}-\mathrm{PhDi}-\mathrm{Np}$ with $\mathrm{CB}[8]$ was demonstrated by isothermal titration calorimetry (ITC), ${ }^{1} \mathrm{H}$ NMR and diffusion-ordered NMR spectroscopy (DOSY). As shown in the ${ }^{1} \mathrm{H}$ NMR analysis in Fig. S1 (ESI $\dagger$ ), when the molar ratio of $\mathrm{CB}[8]$ to $\mathrm{Np}-\mathrm{PhDi}-\mathrm{Np}$ increased from 0 to 1.0, the peaks of Np moiety shifted up-field, while the peaks of PhDi moiety shifted down-field. These shifting peaks indicated that the $\mathrm{CB}$ [8] combined with $\mathrm{Np}$ moieties of $\mathrm{Np}-\mathrm{PhDi}-\mathrm{Np}$ primarily, acting as the driving force for supramolecular polymerization. When the molar ratio of $\mathrm{CB}[8]$ to $\mathrm{Np}-\mathrm{PhDi}-\mathrm{Np}$ increased from 1.0 to 2.0 , the peaks of PhDi moiety shifted up-field, which indicated that the $\mathrm{CB}[8]$ combined with the PhDi moiety of $\mathrm{Np}-$ PhDi-Np subsequently. The two-step host-guest complexations were also indicated by ITC data, as shown in Fig. 1. The first abrupt change at a molar ratio of $1: 1$ could be ascribed to the complexation between $\mathrm{CB}[8]$ and Np moieties, and the second abrupt change at a molar ratio of $2: 1$ could be ascribed to the complexation between $\mathrm{CB}[8]$ and PhDi moiety. The two-step complexation may lead to the formation of the supramolecular polymer backbone.

Direct evidence for the formation of the supramolecular polymer backbone was demonstrated by DOSY. The diffusion coefficient of $\mathrm{Np}-\mathrm{PhDi}-\mathrm{Np}(0.25 \mathrm{mM})$ in water was $2.80 \times$ $10^{-10} \mathrm{~m}^{2} \mathrm{~s}^{-1}$. After addition of 2 equivalents of $\mathrm{CB}[8]$, the diffusion coefficient was decreased to $1.10 \times 10^{-10} \mathrm{~m}^{2} \mathrm{~s}^{-1}$, which indicated the formation of polymeric species. Taking the ${ }^{1} \mathrm{H}$ NMR data, ITC data and DOSY measurements into account, the supramolecular polymer backbone is formed on the basis of the host-guest complexations between Np-PhDi-Np and $\mathrm{CB}[8]$.

To fabricate a side-chain antibacterial supramolecular polymer, TNAB containing three NpAM moieties was designed as 


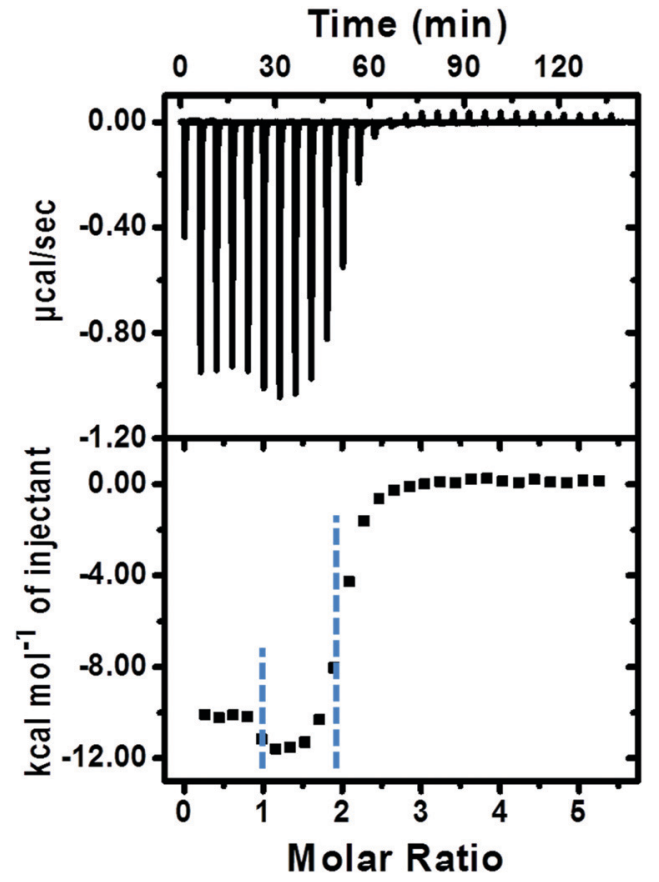

Fig. 1 ITC data (1× PBS buffer, $\left.\mathrm{pH}=7.0,25.0^{\circ} \mathrm{C}\right)$ of $\mathrm{CB}[8](0.25 \mathrm{mM})$ titrated into $\mathrm{Np}-\mathrm{PhDi}-\mathrm{Np}(0.010 \mathrm{mM})$.

the side chains to graft to the supramolecular polymer backbone through self-sorting. The self-sorting among Np, NpAM, PhDi model molecules and $\mathrm{CB}[8]$ was studied by ${ }^{1} \mathrm{H}$ NMR, as demonstrated in Fig. 2. When Np, NpAM, PhDi model molecules and $\mathrm{CB}[8]$ were mixed at a ratio of $2: 1: 1: 2$, only the complexation between $\mathrm{Np}$ and $\mathrm{CB}[8]$ and the complexation of NpAM, PhDi and $\mathrm{CB}[8]$ were observed. The ITC data further demonstrated that $\mathrm{Np}$ could bind with $\mathrm{CB}[8]$ at a ratio of $2: 1$ with a binding constant of $2.25 \times 10^{12} \mathrm{M}^{-2}$. In addition, the NpAM moiety could insert into the supramolecular polymer backbone with a binding constant of $2.01 \times 10^{5} \mathrm{M}^{-1}$, as shown

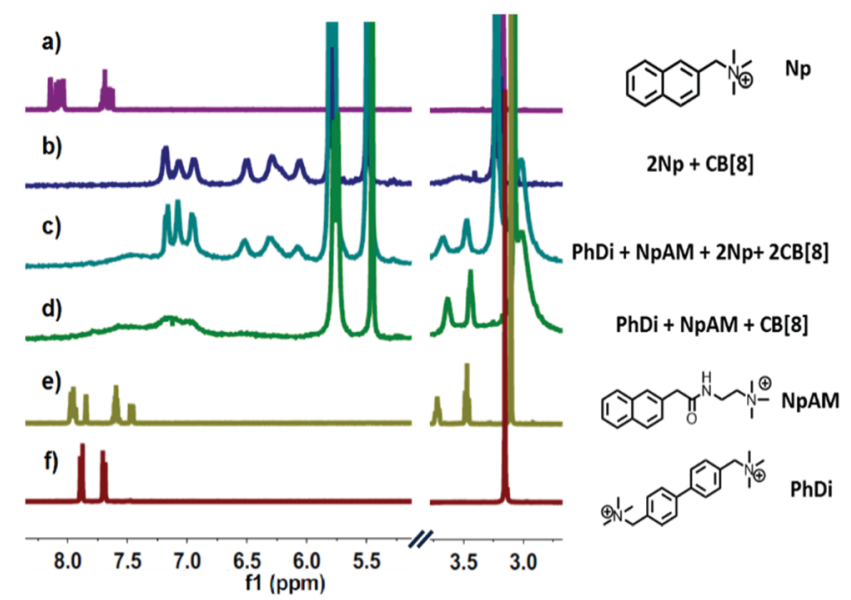

Fig. 2 Partial ${ }^{1} \mathrm{H}$ NMR spectra $\left(400 \mathrm{MHz}, \mathrm{D}_{2} \mathrm{O}, 25.0^{\circ} \mathrm{C}\right)$ of (a) $\mathrm{Np}(2.0 \mathrm{mM})$; (b) $2 \mathrm{~Np}-\mathrm{CB}[8](1.0 \mathrm{mM})$; (c) a mixture of $\mathrm{Np}(2.0 \mathrm{mM}), \mathrm{NpAM}(1.0 \mathrm{mM})$, PhDi (1.0 mM), and $\mathrm{CB}[8](2.0 \mathrm{mM})$; (d) $\mathrm{PhDi}-\mathrm{NpAM}-\mathrm{CB}[8](1.0 \mathrm{mM})$; (e) NpAM (1.0 mM); (f) PhDi (1.0 mM). in Fig. S4 (ESI $\dagger$ ). Based on the self-sorting of the model molecules, TNAB, containing three NPAM moieties, could insert into the supramolecular polymer as side chains for constructing the antibacterial supramolecular polymer.

The formation of the side-chain antibacterial supramolecular polymer was confirmed by analytical ultracentrifugation. As shown in Fig. S5a and b (ESI $\dagger$ ), at a low concentration of $50 \mu \mathrm{M}$, the highest molecular weight of supramolecular polymer backbone was measured as $1.7 \times 10^{4} \mathrm{Da}$, corresponding to a degree of polymerization (DP) of 5 . After addition of TNAB, the molecular weight of the antibacterial supramolecular polymer was increased up to $2.1 \times 10^{4} \mathrm{Da}$. The increased molecular weight indicated that 5 TNAB molecules were grafted to the supramolecular polymer backbone. Although there were three NpAM moieties on TNAB, the same DP of supramolecular backbone and antibacterial supramolecular polymer indicated that the crosslinking among the supramolecular polymer chains was negligible because of the low concentration. In addition, the DP of the antibacterial supramolecular polymer could be increased with increasing concentration of the building blocks. For example, the DP was measured to be 12 at a concentration of $0.50 \mathrm{mM}$, as shown in Fig. S5c (ESI $\dagger$ ). Therefore, the side-chain antibacterial supramolecular polymer is successfully fabricated through selfsorting.

We have demonstrated successfully that antibacterial activity can be enhanced owing to the local enrichment of the antibacterial small molecules through the construction of the side-chain antibacterial supramolecular polymer. For comparison, antibacterial activity of the antibacterial supramolecular polymer, supramolecular polymer backbone and TNAB were investigated. As shown in Fig. 3, the supramolecular polymer backbone displayed almost no antibacterial activity, and the bacterial inhibition ratio of TNAB against ampicillin-resistant E. coli was

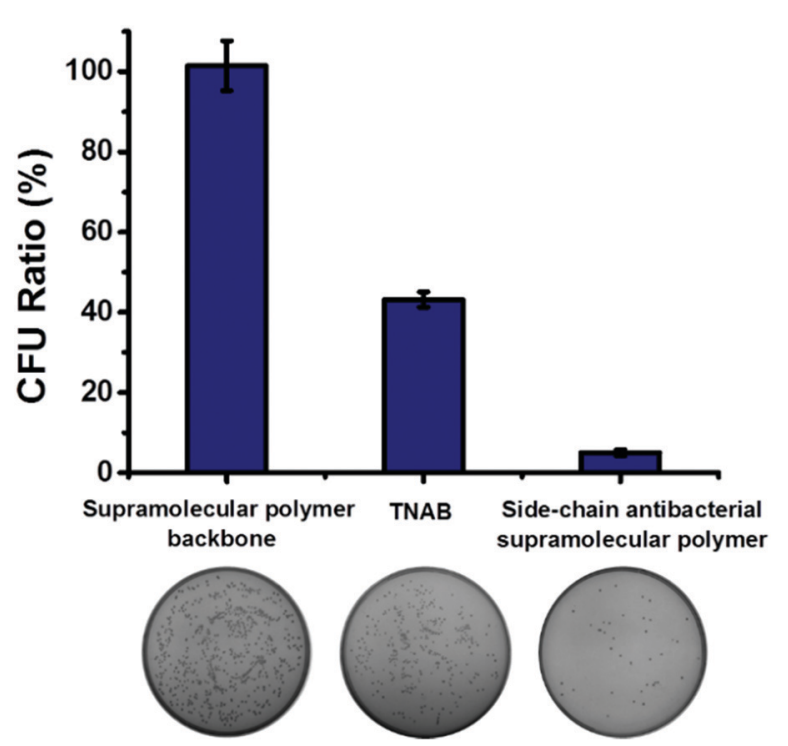

Fig. 3 The colony-forming unit (CFU) ratio of E. coli with antibacterial supramolecular polymer, supramolecular polymer backbone and TNAB. The concentrations of building blocks of supramolecular polymers and TNAB are $50 \mu \mathrm{M}$. 


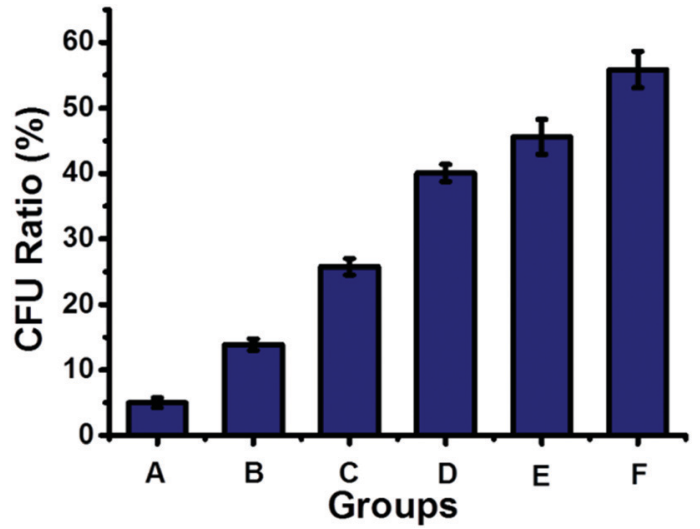

Fig. 4 The antibacterial activity of the antibacterial supramolecular polymer with different amounts of a disassembling agent, naphthalene derivatives (DA shown in Scheme 1). (A) $50 \mu \mathrm{M}$ antibacterial supramolecular polymer; (B) A + $10 \mu \mathrm{M} \mathrm{DA}$; (C) A + $20 \mu \mathrm{M} \mathrm{DA}$; (D) A + $30 \mu \mathrm{M} \mathrm{DA}$; (E) A + $40 \mu \mathrm{M} \mathrm{DA} ;(F) A+50 \mu \mathrm{M}$ DA.

calculated as $57 \%$. When TNAB was grafted to the supramolecular backbone for forming the antibacterial supramolecular polymer, the bacterial inhibition ratio was remarkably increased up to $95 \%$. Therefore, the antibacterial activity can be promoted by fabrication of the antibacterial supramolecular polymer.

The dynamic nature of supramolecular interactions endowed the supramolecular polymer with degradability, which could be used to turn off the antibacterial activity of the antibacterial supramolecular polymer for avoiding long-term drug exposure. The antibacterial supramolecular polymer could be degraded by addition of a disassembling agent (DA), naphthalene derivatives, through competing with the host-guest interaction between Np and $\mathrm{CB}[8]$, as indicated by DOSY shown in Table S1 (ESI $\dagger$ ). Then the antibacterial efficacy could be regulated by the controllable degradation of the antibacterial supramolecular polymer. As shown in Fig. 4, by gradual addition of the DA to the antibacterial supramolecular polymer, the bacterial inhibition ratio was gradually decreased from $95 \%$ to $44 \%$. The controllable degradation of the antibacterial supramolecular polymer could diminish the enrichment of TNAB, leading to the decrease of antibacterial activity. Therefore, the antibacterial efficacy of the antibacterial supramolecular polymer can be well regulated from high to low activity.

$\zeta$-Potential measurements and scanning electron microscopy (SEM) were employed to understand the interactions between the antibacterial supramolecular polymer and bacteria. Upon addition of the antibacterial supramolecular polymer, the surface charge of $E$. coli was altered from $-48.0 \mathrm{mV}$ to $19.9 \mathrm{mV}$ (Table S2, ESI $\dagger$ ), indicating that the positively charged antibacterial supramolecular polymer was adsorbed onto the surface of E. coli. It was demonstrated by SEM that the antibacterial mechanism was membranolysis of the bacteria (Fig. S6, ESI $\dagger$ ). As reported, the hydrophobic groups of antibacterial agents can insert into the membranes of bacteria, resulting in membranolysis. ${ }^{13,16,17}$ By locally enriching the hydrophobic groups of TNAB on the antibacterial supramolecular polymer, the membranolysis of bacteria can be enhanced, thus promoting the antibacterial efficacy.

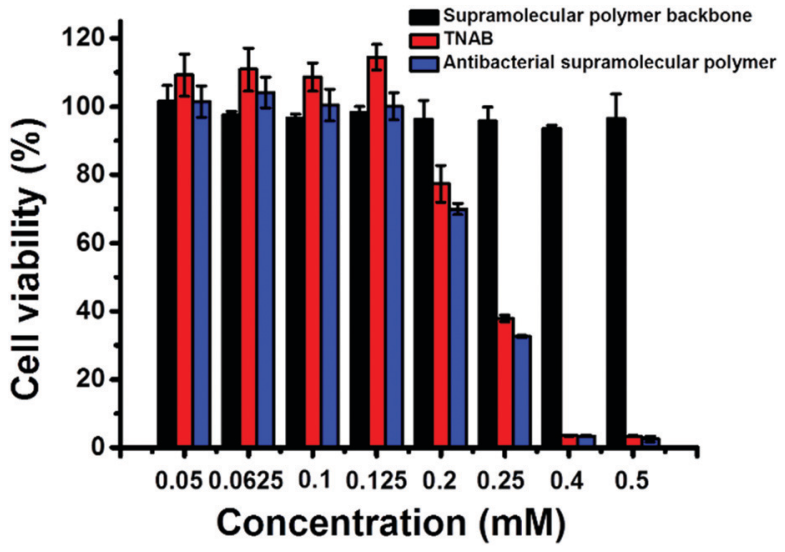

Fig. 5 The cytotoxicity of supramolecular polymer backbone, TNAB and antibacterial supramolecular polymer on mammalian cells ( $\mathrm{HaCaT})$.

The cytotoxicity of TNAB, supramolecular polymer backbone and antibacterial supramolecular polymer on mammalian cells was also investigated by MTT assay. A nonmalignant epithelial cell line, HaCaT, was chosen as representative cells. As shown in Fig. 5, no cytotoxicity was observed for the supramolecular antibacterial polymer, TNAB and supramolecular polymer backbone when their concentrations were lower than $0.125 \mathrm{mM}$. The antibacterial supramolecular polymer and TNAB exhibited cytotoxicity when their concentrations were higher than $0.125 \mathrm{mM}$. However, the supramolecular polymer backbone displayed no clear cytotoxicity even if the concentration was increased up to $0.50 \mathrm{mM}$. These results suggest that the fabrication of the antibacterial supramolecular polymer is a potential biocompatible strategy for further medical treatment.

\section{Conclusions}

In conclusion, we have successfully fabricated a side-chain antibacterial supramolecular polymer via the self-sorting strategy. The side-chain antibacterial supramolecular polymer exhibits enhanced antibacterial efficacy and controllable degradation. Besides E. coli, this kind of supramolecular polymeric antibacterial material could be used for killing other kinds of microbes. In addition, it is anticipated that other antibiotic reagents may also be supramolecularly polymerized through this method, thus providing a general strategy for building degradable polymer antibiotics with enhanced antibacterial efficacy to fight against drug-resistant bacteria.

\section{Conflicts of interest}

There are no conflicts to declare.

\section{Acknowledgements}

This work was financially supported by the National Natural Science Foundation of China $(21434004,21821001,91527000)$ and the Tsinghua University Initiative Research Project (20181080084). 


\section{Notes and references}

1 Y. Qian, D. Zhang, Y. Wu, Q. Chen and R. Liu, Acta Polym. Sin., 2016, 1300-1311.

2 C. Zhu, L. Liu, Q. Yang, F. Lv and S. Wang, Chem. Rev., 2012, 112, 4687-4735.

3 Y. Yang, P. He, Y. Wang, H. Bai, S. Wang, J.-F. Xu and X. Zhang, Angew. Chem., Int. Ed., 2017, 56, 16239-16242.

4 S. E. Rossiter, M. H. Fletcher and W. M. Wuest, Chem. Rev., 2017, 117, 12415-12474.

5 G. D. Wright, ACS Infect. Dis., 2015, 1, 80-84.

6 I. B. Seiple, Z. Zhang, P. Jakubec, A. Langlois-Mercier, P. M. Wright, D. T. Hog, K. Yabu, S. R. Allu, T. Fukuzaki, P. N. Carlsen, Y. Kitamura, X. Zhou, M. L. Condakes, F. T. Szczypiński, W. D. Green and A. G. Myers, Nature, 2016, 533, 338-345.

7 D. J. Payne, M. N. Gwynn, D. J. Holmes and D. L. Pompliano, Nat. Rev. Drug Discovery, 2007, 6, 29-40.

8 H. Bai, X. Fu, Z. Huang, F. Lv, L. Liu, X. Zhang and S. Wang, ChemistrySelect, 2017, 2, 7940-7945.

9 W. A. Velema, J. P. van der Berg, M. J. Hansen, W. Szymanski, A. J. M. Driessen and B. L. Feringa, Nat. Chem., 2013, 5, 924-928.

10 W. Szymanski, J. M. Beierle, H. A. V. Kistemaker, W. A. Velema and B. L. Feringa, Chem. Rev., 2013, 113, 6114-6178.

11 H. Bai, F. Lv, L. Liu and S. Wang, Chem. - Eur. J., 2016, 22, 11114-11121.

12 Z. Huang, H. Zhang, H. Bai, Y. Bai, S. Wang and X. Zhang, ACS Macro Lett., 2016, 5, 1109-1113.

13 H. Bai, H. Yuan, C. Nie, B. Wang, F. Lv, L. Liu and S. Wang, Angew. Chem., Int. Ed., 2015, 54, 13208-13213.

14 X. Chen, F. Wang, J. Y. Hyun, T. Wei, J. Qiang, X. Ren, I. Shin and J. Yoon, Chem. Soc. Rev., 2016, 45, 2976-3016.

$15 \mathrm{X} . \mathrm{Li}, \mathrm{S}$. Lee and J. Yoon, Chem. Soc. Rev., 2018, 47, 1174-1188.

16 L. Chen, H. Bai, J.-F. Xu, S. Wang and X. Zhang, ACS Appl. Mater. Interfaces, 2017, 9, 13950-13957.

17 Y. Yang, Z. Cai, Z. Huang, X. Tang and X. Zhang, Polym. J., 2018, 50, 33-44.

18 Y. Liu and J. A. Imlay, Science, 2013, 339, 1210-1213.

19 M. Garland, S. Loscher and M. Bogyo, Chem. Rev., 2017, 117, 4422-4461.

20 W. Kim, W. Zhu, G. L. Hendricks, D. Van Tyne, A. D. Steele, C. E. Keohane, N. Fricke, A. L. Conery, S. Shen, W. Pan, K. Lee, R. Rajamuthiah, B. B. Fuchs, P. M. Vlahovska, W. M. Wuest, M. S. Gilmore, H. Gao, F. M. Ausubel and E. Mylonakis, Nature, 2018, 556, 103-107.

21 B. S. Li, R. Wen, S. Xue, L. Shi, Z. Tang, Z. Wang and B. Z. Tang, Mater. Chem. Front., 2017, 1, 646-653.

22 G. Huang, R. Wen, Z. Wang, B. S. Li and B. Z. Tang, Mater. Chem. Front., 2018, 2, 1884-1892.

23 P. I. O’Daniel, Z. Peng, H. Pi, S. A. Testero, D. Ding, E. Spink, E. Leemans, M. A. Boudreau, T. Yamaguchi, V. A. Schroeder, W. R. Wolter, L. I. Llarrull, W. Song, E. Lastochkin, M. Kumarasiri, N. T. Antunes, M. Espahbodi, K. Lichtenwalter, M. A. Suckow, S. Vakulenko, S. Mobashery and M. Chang, J. Am. Chem. Soc., 2014, 136, 3664-3672.
24 M. Zhang, P.-P. Zhu, P. Xin, W. Si, Z.-T. Li and J.-L. Hou, Angew. Chem., Int. Ed., 2017, 56, 2999-3003.

25 X. Li, D. Lee, J.-D. Huang and J. Yoon, Angew. Chem., Int. Ed., 2018, 57, 9885-9890.

26 X. Li, H. Bai, Y. Yang, J. Yoon, S. Wang and X. Zhang, Adv. Mater., 2019, 31, 1805092.

27 P.-Z. Chen, L.-Y. Niu, H. Zhang, Y.-Z. Chen and Q.-Z. Yang, Mater. Chem. Front., 2018, 2, 1323-1327.

28 L. Yang, X. Tan, Z. Wang and X. Zhang, Chem. Rev., 2015, 115, 7196-7239.

29 J.-F. Xu, Y.-Z. Chen, D. Wu, L.-Z. Wu, C.-H. Tung and Q.-Z. Yang, Angew. Chem., Int. Ed., 2013, 52, 9738-9742.

30 X. Ma and H. Tian, Acc. Chem. Res., 2014, 47, 1971-1981.

31 R. Sun, C. Xue, X. Ma, M. Gao, H. Tian and Q. Li, J. Am. Chem. Soc., 2013, 135, 5990-5993.

32 H.-Q. Peng, X. Zheng, T. Han, R. T. K. Kwok, J. W. Y. Lam, X. Huang and B. Z. Tang, J. Am. Chem. Soc., 2017, 139, 10150-10156.

33 D.-S. Guo and Y. Liu, Chem. Soc. Rev., 2012, 41, 5907-5921. 34 G. Yu, X. Zhao, J. Zhou, Z. Mao, X. Huang, Z. Wang, B. Hu, Y. Liu, F. Zhang, Z. He, O. Jacobson, C. Gao, W. Wang, C. Yu, X. Zhu, F. Huang and X. Chen, J. Am. Chem. Soc., 2018, 140, 8005-8019.

35 J. D. Barrio, P. N. Horton, D. Lairez, G. O. Lloyd, C. Toprakcioglu and O. A. Scherman, J. Am. Chem. Soc., 2013, 135, 11760-11763.

36 C. Fouquey, J.-M. Lehn and A.-M. Levelut, Adv. Mater., 1990, 2, 254-257.

37 U. S. Schubert, O. Hien and C. Eschbaumer, Macromol. Rapid Commun., 2000, 21, 1156-1161.

38 M. Burnworth, L. Tang, J. R. Kumpfer, A. J. Duncan, F. L. Beyer, G. L. Fiore, S. J. Rowan and C. Weder, Nature, 2011, 472, 334-337.

39 J. Sautaux, L. M. Espinosa, S. Balog and C. Weder, Macromolecules, 2018, 51, 5867-5874.

40 T. Aida, E. W. Meijer and S. I. Stupp, Science, 2012, 335, 813-817.

41 J. Murray, K. Kim, T. Ogoshi, W. Yao and B. C. Gibb, Chem. Soc. Rev., 2017, 46, 2479-2496.

42 A. Harada, Y. Takashima and H. Yamaguchi, Chem. Soc. Rev., 2009, 38, 875-882.

43 S. Yang, A. V. Ambade and M. Weck, Chem. Soc. Rev., 2011, 40, 129-137.

44 T. F. A. de Greef and E. W. Meijer, Nature, 2008, 453, 171-173. 45 X. Hou, C. Ke, Y. Zhou, Z. Xie, A. Alngadh, D. T. Keane, M. S. Nassar, Y. Y. Botros, C. A. Mirkin and J. F. Stoddart, Chem. - Eur. J., 2016, 22, 12301-12306.

46 J.-F. Xu and X. Zhang, Acta Polym. Sin., 2017, 37-49.

47 K.-D. Zhang, J. T. Hanifi, Y. Zhang, A. C.-H. Sue, T.-Y. Zhou, L. Zhang, X. Zhao, Y. Liu and Z.-T. Li, J. Am. Chem. Soc., 2013, 135, 17913-17918.

48 Z. Zhang, Y. Luo, J. Chen, S. Dong, Y. Yu, Z. Ma and F. Huang, Angew. Chem., Int. Ed., 2011, 50, 1397-1401.

49 H. Wang, X. Ji, Z. Li, C. N. Zhu, X. Yang, T. Li, Z. L. Wu and F. Huang, Mater. Chem. Front., 2017, 1, 167-171.

50 Y. Liu, Y. Zhang, H. Zhu, H. Wang, W. Tian and B. Shi, Mater. Chem. Front., 2018, 2, 1568-1573. 
51 X. Yan, D. Xu, X. Chi, J. Chen, S. Dong, X. Ding, Y. Yu and F. Huang, Adv. Mater., 2012, 24, 362-369.

52 S. Dong, J. Leng, Y. Feng, M. Liu, C. J. Stackhouse, A. Schçnhals, L. Chiappisi, L. Gao, W. Chen, J. Shang, L. Jin, Z. Qi and C. A. Schalley, Sci. Adv., 2017, 3, eaao0900. 53 X. Yan, Z. Liu, Q. Zhang, J. Lopez, H. Wang, H.-C. Wu, S. Niu, H. Yan, S. Wang, T. Lei, J. Li, D. Qi, P. Huang, J. Huang, Y. Zhang, Y. Wang, G. Li, J. B.-H. Tok, X. Chen and Z. Bao, J. Am. Chem. Soc., 2018, 140, 5280-5289.

54 Z. Huang, B. Qin, L. Chen, J.-F. Xu, C. F. J. Faul and X. Zhang, Macromol. Rapid Commun., 2017, 38, 1700312.

55 Y.-Y. Huang, Y. Tian, X.-Q. Liu, Z. Niu, Q.-Z. Yang, V. Ramamurthy, C.-H. Tung, Y.-Z. Chen and L.-Z. Wu, Mater. Chem. Front., 2018, 2, 1893-1899.

56 S. Ogi, V. Stepanenko, K. Sugiyasu, M. Takeuchi and F. Würthner, J. Am. Chem. Soc., 2015, 137, 3300-3307.

57 M. M. Safont-Sempere, G. Fernández and F. Würthner, Chem. Rev., 2011, 111, 5784-5814.
58 J.-M. Lehn, Science, 2002, 295, 2400-2403.

59 S. Liu, C. Ruspic, P. Mukhopadhyay, S. Chakrabarti, P. Y. Zavalij and L. Isaacs, J. Am. Chem. Soc., 2005, 127, 15959-15967.

60 M. Hutin, C. J. Cramer, L. Gagliardi, A. R. M. Shahi, G. Bernardinelli, R. Cerny and J. R. Nitschke, J. Am. Chem. Soc., 2007, 129, 8774-8780.

61 T. F. A. de Greef, G. Ercolani, G. B. W. L. Ligthart, E. W. Meijer and R. P. Sijbesma, J. Am. Chem. Soc., 2008, 130, 13755-13764.

62 B. H. Northrop, Y. Zheng, K. Chi and P. J. Stang, Acc. Chem. Res., 2009, 42, 1554-1563.

63 W. Jiang and C. A. Schalley, Proc. Natl. Acad. Sci. U. S. A., 2009, 106, 10425-10429.

64 L. Cera and C. A. Schalley, Chem. Sci., 2014, 5, 2560-2567.

65 Z. Huang, L. Yang, Y. Liu, Z. Wang, O. A. Scherman and X. Zhang, Angew. Chem., Int. Ed., 2014, 53, 5351-5355.

66 L. Chen, Z. Huang, J.-F. Xu, Z. Wang and X. Zhang, Polym. Chem., 2016, 7, 1397-1404. 